\title{
Remote Environmental Data Analysis Using Sounding Rocket
}

\author{
M. M. R. Manu ${ }^{* 1}$, Rajib Saha ${ }^{* 2}$, S. N. M. Azizul Hoque ${ }^{\# 3}$, Aminul Hoque ${ }^{* 4}$ \\ *Department of Electrical and Electronic Engineering, Eastern University, Dhaka, Bangladesh \\ "Department of Physical Sciences, Independent University, Bangladesh (IUB) \\ 11manu20133023@gmail.com, ${ }^{2}$ joy.rajibsaha@gmail.com, ${ }^{4}$ ahoque.eee@easternuni.edu.bd, ${ }^{3}$ ahoque@iub.edu.bd
}

\begin{abstract}
In this study a low-cost environmental data monitoring system for sounding rocket is developed based on Internet of Things (IoT) and several sensors. Rocket sounding can investigate the physical and chemical properties of the atmosphere. We propose to build rocket operated by Raspberry Pi with low cost monitoring sensors that can provide real-time altitude, pressure, humidity and temperature with 0.1 second time interval. Temporal resolution of the low-cost gas sensors is one second, therefore, can only be used to monitor the surrounding environment before and during the flight operation. Experimental and simulated values are analyzed and compared to understand the atmospheric dynamics. This study will help space physics community to develop high altitude sounding rocket.
\end{abstract}

Keyword: Internet of Things, Rocket Sounding, Raspberry Pi

\section{INTRODUCTION}

The objective of this work is to assemble a compact small model rocket to monitor environmental data using IoT. In this work, the basic challenge of sounding rocket is to deal the dynamic nature of the system. Here the nature of the system depends on the type of fuel, atmospheric dynamics at different altitude, weight of the payload and parachute. The typical flight duration of sounding rockets to reach the apogee is 2-20 seconds [1]. Therefore, sufficient amount of data collection from the low-cost sensors is the challenging part in this research. Raspberry Pi (RPi) can overcome the challenges.

Many agencies from several countries have done scientific experiments, which are popularly called sounding rockets [1]. National Aeronautics and Space Administration (NASA) established NASA Sounding Rocket Program in 1959 [2]. Recent works on sounding rockets and the references are given [3]-[8]. Model rockets face some limitations such as comparatively low range, short span of the mission and limited payload capability. High-Altitude Balloons (HAB) [9]-[10] and unmanned aerial vehicles (UAV) commonly known as drones [11] have relatively longer mission life. Despite this fact our model rocket is relatively inexpensive to collect valuable data which may use in future to develop a sounding rocket. In fact, this project shows that the cost of sounding rocket is less expensive than operating HAB and drones. This paper is valuable to the Space Physics Community and the atmospheric researcher who regularly deal with the remote-control space weather and meteoroidal data.

In this paper relatively high temporal resolution (i.e., $0.1 \mathrm{sec}$ ) low-cost sensors record pressure, altitude and temperature. The data are stored in a micro SD card as well as firebase server. Atmospheric data such as measuring $\mathrm{SO}_{2}, \mathrm{NO}_{2}, \mathrm{CO}_{2}$ and $\mathrm{CH}_{4}$ are not collected from the payload due to the limitation of relatively poor temporal resolution (e.g., $1 \mathrm{sec}$ ) of the sensors. Atmospheric data, therefore, are analysed to monitor the surrounding environment around the launch platform and were compared with the data collected from air pollutants monitoring agency, such as, Airnow [12] and Bangladesh Meteorological Department (BMD) [13].

In the section 2, several types of model rockets and rocket engines are discussed. In the section 3-5, work flow diagram are shown while testing the model rocket is discussed. Finally, the obtained results are compared with the data collected from Open Rocket Simulation Software [26] and conclusions thereafter.

\section{Preliminary work}

Basically, apogee of the model rockets depends on the category of the rocket fuel, air drag coefficient, wind velocity and gravitational force of the Earth. Model rocket motors generally depends on impulse [16] commonly measured in Newton Second (N-s). In this study, Sugar Rocket Engine [15] is prepared for launching the model rocket.

\section{A. Rocket Engine:}

Table 1 shows the types of rocket engine. In this project class $\mathrm{E}$ with $40 \mathrm{~N}$-s impulse (popularly known as E40) equivalent rocket motor is made in the lab from the mixture of chemical oxidizer (potassium nitrate), granulated sugar and clay. Care should be taken to use the potassium nitrate as it is considered as an explosive powder. The white mix (Fig. 1) is made by mixing 20 gm grind sugar added with 35 gm of potassium titrate. Hard clay is used on both ends of the white mixture to build enough pressure for rocket launching. The fuel is kept inside the schedule 40 PVC pipes where the inner diameter is $2.4 \mathrm{~cm}$ and the outer diameter is $2.6 \mathrm{~cm}$ 
(Fig. 1). PVC material is ideal for pressure resistor and thermal insulator. $6 \mathrm{~mm}$ nozzle were created using the 7/32" drill bit. The rocket engine is attached with 1-meter-long and $0.5 \mathrm{~cm}$ thin wooden rod at the launch platform (Fig. 1). Finally, battery-operated remote-control ignition is attached at the end of the nozzle to launch the rocket safely from the platform.

TABLE 1. Rocket Engine Comparison [23]

\begin{tabular}{|c|c|}
\hline Class & Time Impulse [N-s] \\
\hline A & $1.26-2.50$ \\
\hline B & $2.51-5.00$ \\
\hline C & $5.01-10.00$ \\
\hline D & $10.01-20.00$ \\
\hline E & $20.01-40.00$ \\
\hline F & $40.01-80.00$ \\
\hline G & $80.01-160$ \\
\hline H & $160.01-320$ \\
\hline
\end{tabular}

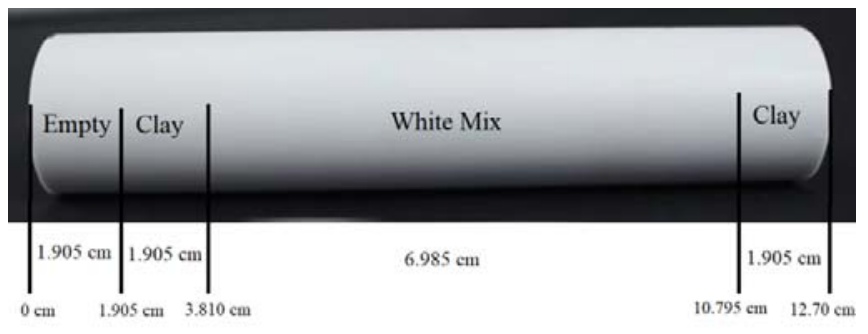

(a)

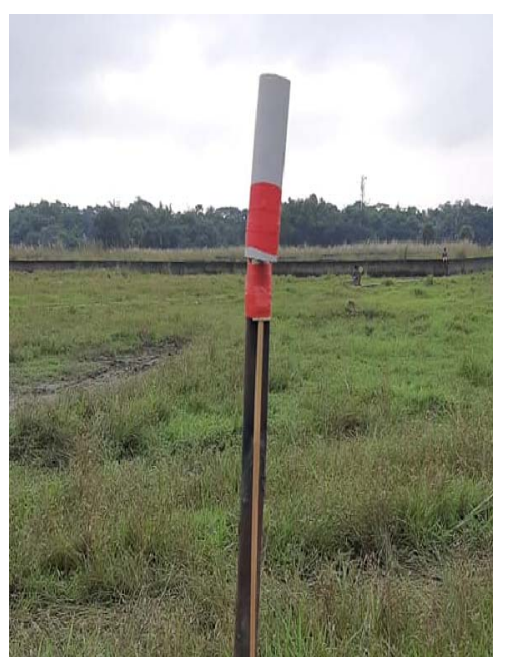

(b)

Fig. 1. (a) Mixing ratio of the Rocket Fuel. (b) Rocket fuel in a launch platform

B. Design of the Model Rocket

Model rocket designs normally follow the structure as shown in fig. 2. Fig. 2 (upper terminal) is the typical model rocket design [14]. Fig. 2 (lower terminal) is the simulated rocket design [26] based on our model rocket. In this experiment, rocket fuel, recovery system, nose cone, payload, fins for balance purpose are used. Inside the payload, several sensors and Raspberry Pi are inserted. PVC is used as a thermal insulator to separate the fuel and the payload. Details of the sensors are also discussed in section 4 . 


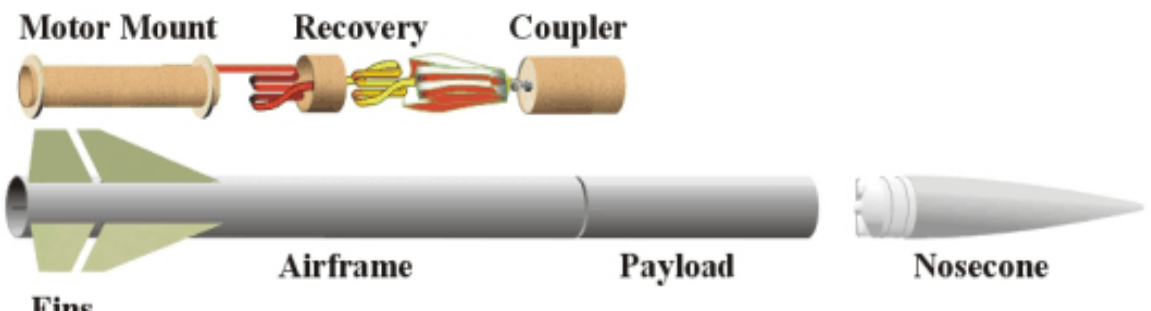

(a)

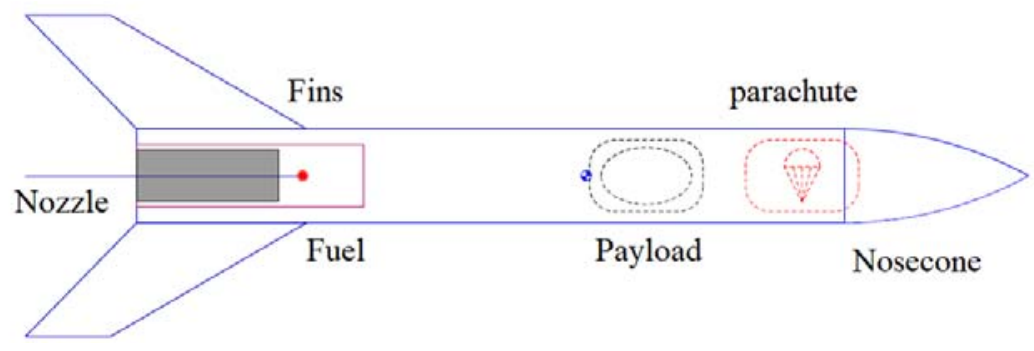

(b)

Fig. 2. (a) Typical model rocket design [14]. (b) Simulated model rocket design.

\section{Parameters to Measure}

To measure a set of parameters during the flight interval is the most challenging part of the study. Without the precise time rest of the data cannot be adequately analysed. In this project, Raspberry Pi internal clock ensures accuracy of time in $100 \mathrm{~ns}$ interval [17]. The expected temporal resolution of the sensors is 0.1 second. Therefore, data is collected 0.1 second interval. Though, horizontal position (latitude and longitude) is one of the fundamental parameters it is not measured directly from the sensors. Usually the range of the flight not exceed 50 meters from the launch site. However, based on the initial and final position of the rocket using normal ruler and Global Positioning System (GPS), the range of the trajectory can be calculated. Altitude is another important measurement for the sounding rocket project. BMP 180 sensor is ideal to measure altitude with an accuracy of $8 \mathrm{~cm}$ spatial resolution and $20 \mathrm{~ms}$ temporal resolution. Linear velocity and acceleration is always an important factor. With the positional (latitudinal and longitudinal) data three-dimensional velocity and acceleration can be recovered. In most of the sounding rocket project, attitude (orientation of a rigid body) is measured using magnetometer and accelerometer [18]. In this project, the attitude was not measured as magnetometer was not readily available. Normal pressure and sea level pressure is collected from DHT 11 sensor. Horizontal wind speed is one of the important parameters during the operation period. Wind speed can be measured using simple cup anemometer [19] consisting of three or four cups, conical or hemispherical in shape, mounted symmetrically about a vertical spindle. LiDAR/SoDAR is a sophisticated device to measure wind speed. In this study, the wind velocity and directions were obtained from Bangladesh Meteorological Department (BMD) [13], NOAA [20] and windy [21].

\section{PAyload}

Inside the rocket, Raspberry Pi microprocessor, micro SD card, WiMAX and battery are inserted covered by bubble wrap.

\section{A. Microprocessor}

The microprocessor is the brain of the payload. Rest of the components in the payload are connected to it. In this project, RPi $0 \mathrm{~W}$ model is used as a microprocessor (Fig. 3). RPi $0 \mathrm{~W}$ is a lightweight and powerful single board computer, running with an operating system Raspbian, a Debian-based Linux operating system, which is free and developed for the RPi. The RPi has a built-in wireless LAN, Bluetooth 4.1, 1.0 GHz single core CPU, 512 MB RAM, mini HDMI and USB On-The-Go ports, micro USB power port and 40 General Purpose Input/output (GPIO) pins which helps to keep fairly fast computing and processing power. The RPi continuously reads parameter data from various sensors based on the corresponding connection pins. The RPi also upload the monitored data to the cloud through the Wi-Fi module, and the cloud stores the data. 


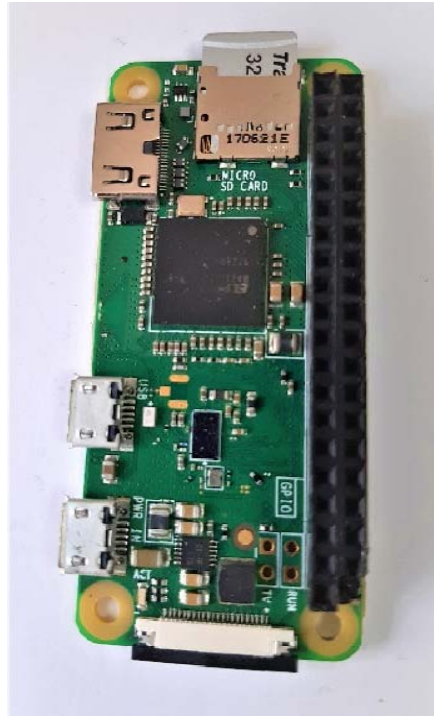

(a)

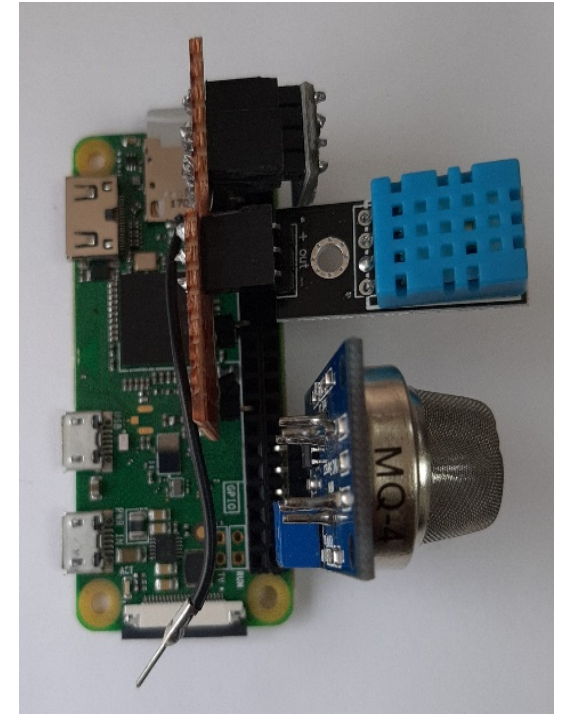

(b)

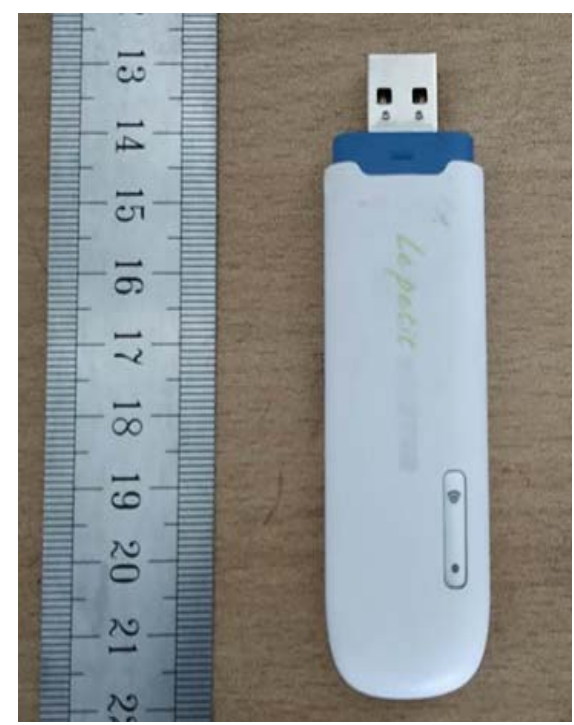

(c)

Fig. 3. (a) RPi without sensors, (b) RPi with sensors, (c) WiMAX

\section{B. Data Recording and Remote Communication}

For our current design, perception of small, light and availability, the most obvious solution is a micro SD card. There is a micro SD card slot in our RPi. 32 GB micro SD card is inserted in RPi OW to store data. Besides, Teletalk WiMAX is used (Fig. 3) to collect the real time data. Using the teletalk internet connection, the real time data is transferred into the firebase console. Firebase projects are backed by Google cloud platform which is free for the user. The data is stored in json format and can be plotted to analyse the flight mission.

\section{OPERATION OF RPI}

Fig. 4 shows the basic operation of the RPi which is popularly known as Internet of Raspberry Things (IoRT). BMP 180 and DHT 11 sensors provides temperature, altitude, atmospheric pressure and sea level pressure data. Real time data is monitored by the user as well as the data is stored in the micro SD card. 


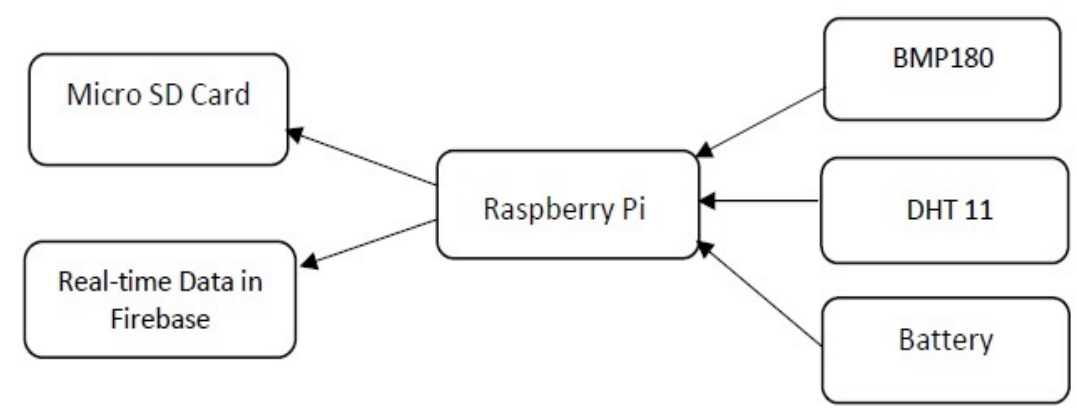

Fig. 4. Basic Operation of RPi

\section{ROCKET SimUlation}

Rocket simulation is performed with the help of open rocket simulation software (Fig. 5). In the simulation the rocket motor, payload, parachutes, dimension of the rocket, material of the rocket, air coefficient, surrounding wind speed, latitudinal and longitudinal position of the launch platform were the input parameters. All input values are identical of the original flight of the test rocket. The length is $35.4 \mathrm{~cm}$, diameter is $3.3 \mathrm{~cm}$, total mass is $291 \mathrm{gm}$.

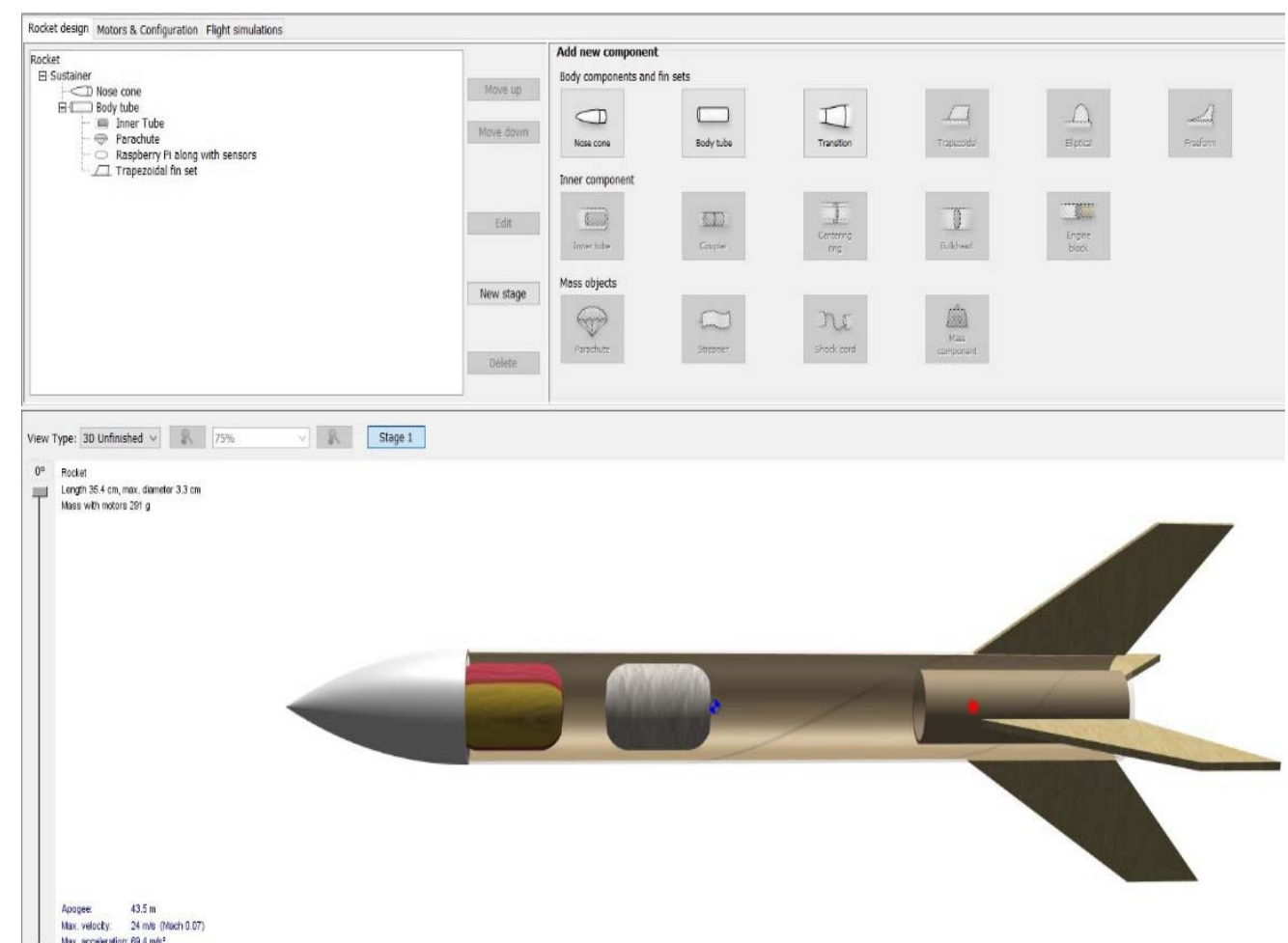

Fig. 5. Design of the simulated rocket. Parachute inside the nosecone, payload in the middle, fuel and fin in the back

Fig. 6 shows the flight simulation graph. The red, green and blue line indicates altitude, velocity and acceleration respectively. The apogee, maximum acceleration, maximum velocity is $43.5 \mathrm{~m}, 69.4 \mathrm{~m} / \mathrm{s}^{2}, 24 \mathrm{~m} / \mathrm{s}$ respectively. The total duration of the flight is 6 seconds. 


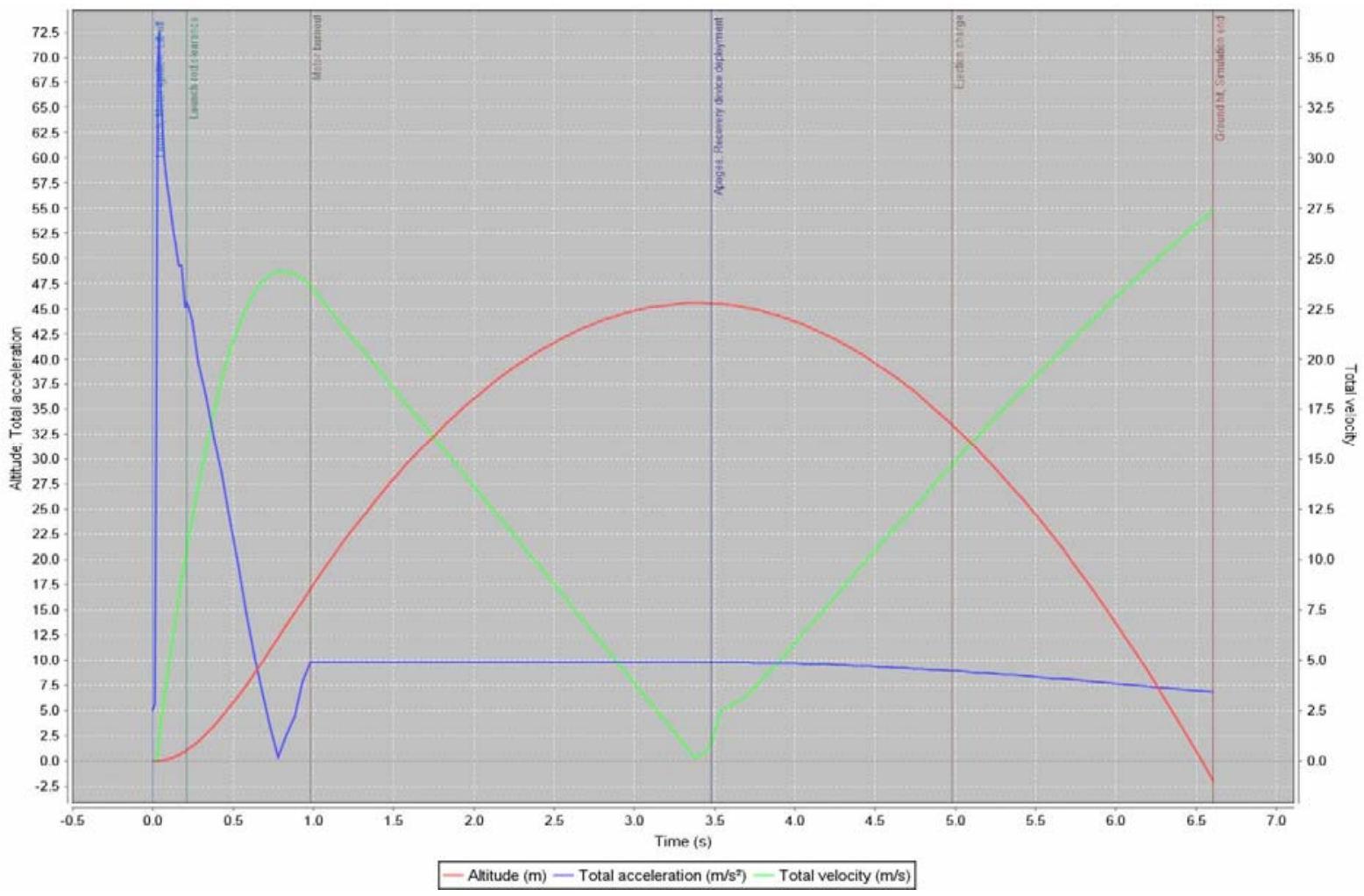

Fig. 6. Fight Simulation Graph

VII. LAUNCH Procedure

Before launching the rocket with fuel, the model rocket need to be tested by dropping from the altitude similar to apogee calculated from the simulation. The model rocket requires to be airborne. At first, object having equal weight of the model rocket is dropped attached with parachute (Fig. 7 (a), Fig. 8 (a)). Simulation is performed using Open Rocket Simulation Software to ensure the safe landing. Data from the simulation indicates that decent landing velocity of the payload should be less than $7 \mathrm{~m} / \mathrm{s}$. This ensures the rocket falling from certain altitude with the parachute will remain safe. A second drop is then made with the instruments and monitor the data (Fig. 7 (b), Fig. 8 (a)).

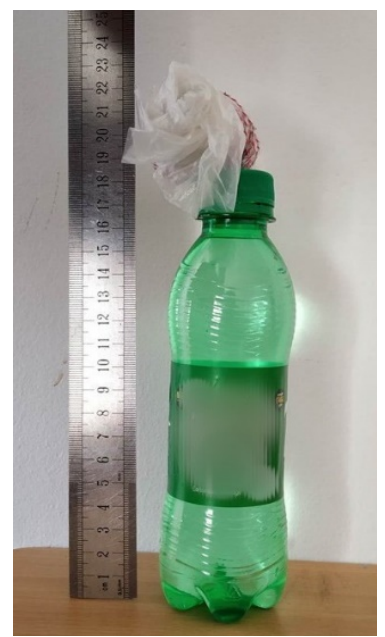

(a)

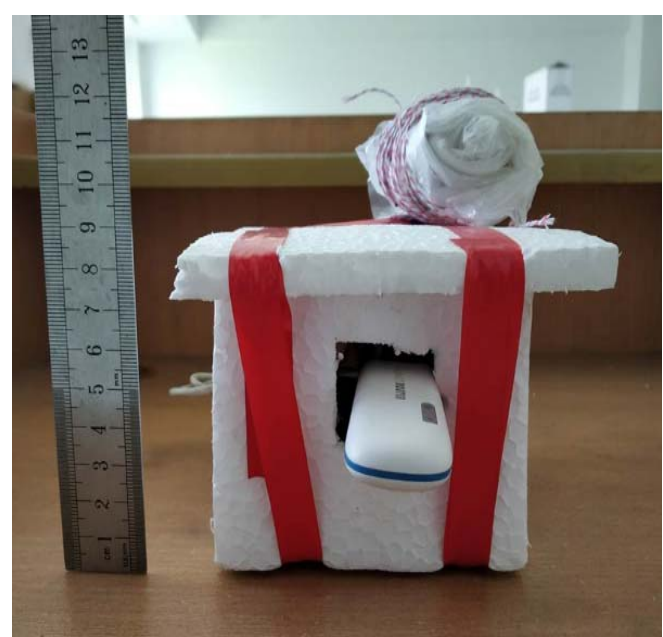

(b)

Fig. 7. (a) Parachute with dummy payload. (b) Parachute with payload 

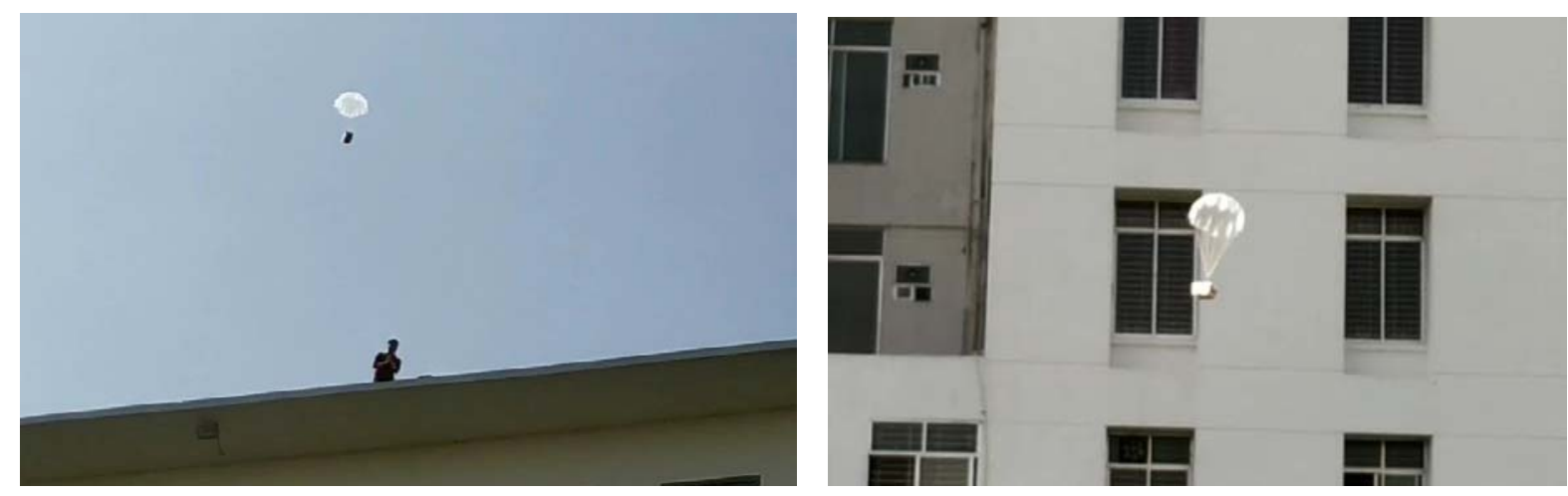

Fig. 8. Free fall test using Parachute at Eastern University Permanent Campus

Launch site should be flat and clear off any obstacles. For safety reason, minimum distance from the launch platform should be 9 meter. 10-meter-long wire is used to connect the ignition with the battery-operated switch. The ignition was connected with the nozzle of the fuel. Launch platform must be clear of flammable materials. The platform is the made by wooden rigid rod and the angle should be vertical. In this work, ESTES manual is followed [24]-[25] to launch the rocket as shown in the table 2.

TABLE 2. Rocket Launch Checklist

\begin{tabular}{|c|c|}
\hline 1 & Select the launch setup \\
\hline 2 & Audible countdown \\
\hline 3 & Check the area is clear \\
\hline 4 & Place rocket on the launch pad \\
\hline 5 & Install the igniter in the rocket motor \\
\hline 6 & Verify the engine is secured \\
\hline 7 & Place the flame-resistant wadding and parachute \\
\hline 8 & Verify the weather condition \\
\hline
\end{tabular}

Finally, flight test with the fuel is performed using trial error method. Table 3 shows the summary of the flight test. E40 fuel without the payload and parachute were tested for five times (Flight No. 1-5 in the column 1). Four tests (flight No. 6-9) were performed with the prototype rocket without payload and parachute. Final test (test no. 10) was performed with the payload and parachute.

TABLE 3. Summary of the Flight Test

\begin{tabular}{|r|c|c|c|}
\hline $\begin{array}{c}\text { Flight } \\
\text { No. }\end{array}$ & Rocket Arrangement & Flight Status and Flight Path & Comments \\
\hline 1 & Rocket Fuel only (Fig. 9 (a)) & Fuel comes out comes out, Failed & $\begin{array}{c}\text { Inappropriate ratio of the } \\
\text { white mixture }\end{array}$ \\
\hline 2 & Rocket Fuel only (Fig. 9 (b)) & Failed to build up pressure & Thin width of the fuel pipe \\
\hline 3 & Rocket Fuel only & Failed & Position of nozzle \\
\hline 4 & Rocket Fuel only & Failed & Position of ignition \\
\hline 5 & Rocket Fuel only (Fig. 9 (c)) & Failed & Selection of clay \\
\hline 6 & Rocket Fuel only (Fig: 10 (a)) & 2 m apogee, $50^{0}$ inclination & $\begin{array}{c}20 \text { cm stick stuck between } \\
\text { fuel and launch platform }\end{array}$ \\
\hline 7 & $\begin{array}{c}\text { Rocket Fuel only (Fig: 10 (b), } \\
\text { (c)) }\end{array}$ & $\begin{array}{c}\text { Clockwise wobble with 10 } \\
\text { inclination from vertical axis }\end{array}$ & $\begin{array}{c}\text { Asymmetric shape (Fig. 11 } \\
\text { (a)) }\end{array}$ \\
\hline 8 & $\begin{array}{c}\text { Rocket Fuel and dummy rocket } \\
\text { (without payload and } \\
\text { parachute) (Fig. 11 (a)) }\end{array}$ & Helicoidal path (Fig. 11 (c)) \\
\hline 9 & $\begin{array}{c}\text { Rocket Fuel and prototype } \\
\text { rocket (Fig. 12) }\end{array}$ & $\begin{array}{c}1.5 \text { m apogee. (Fig. 12) } \\
\text { parachute }\end{array}$ & $\begin{array}{c}\text { Stuck with the launch } \\
\text { platform (Fig. 12 (a)) }\end{array}$ \\
\hline 10 & $\begin{array}{c}\text { Rocket Fuel with payload and } \\
\text { with 10 } 10^{0} \text { inclination from vertical } \\
\text { axis (Fig. 9(a), 9(b)) }\end{array}$ & \\
\hline
\end{tabular}




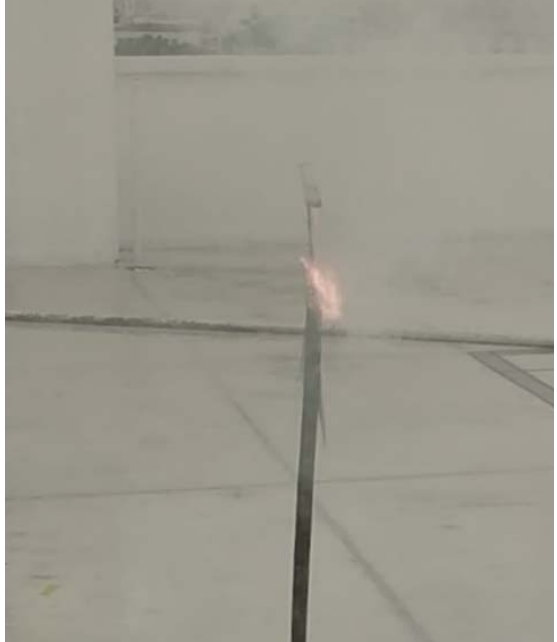

(a)

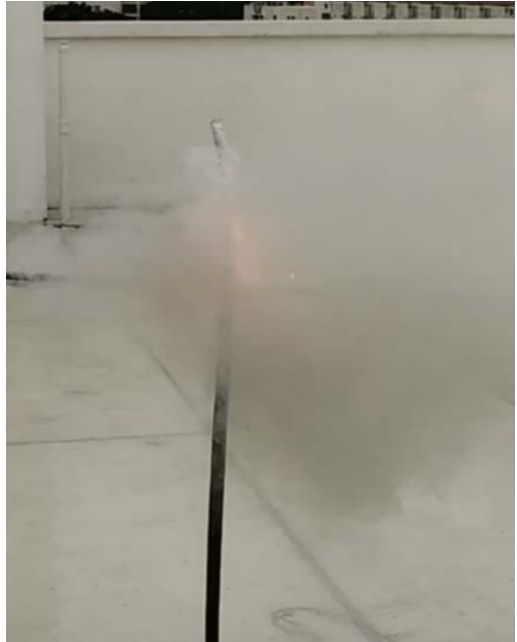

(b)

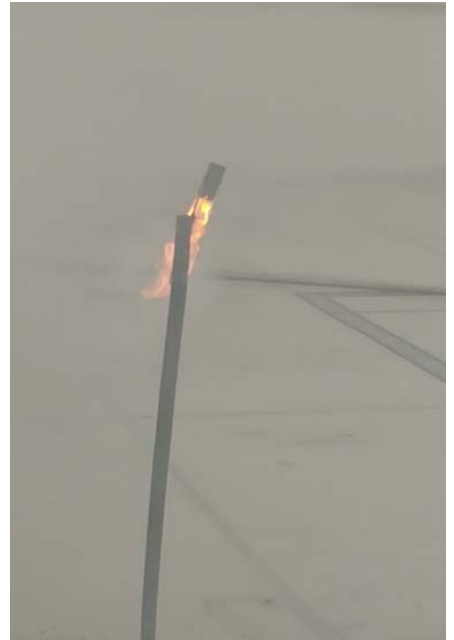

(c)

Fig. 9. (a) Inappropriate fuel mixture. (b) Thin with of the pipe. (c) Position of the ignition

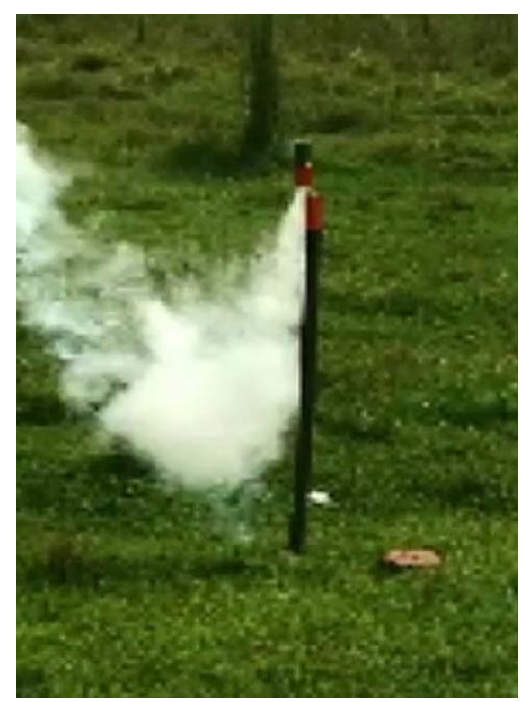

(a)

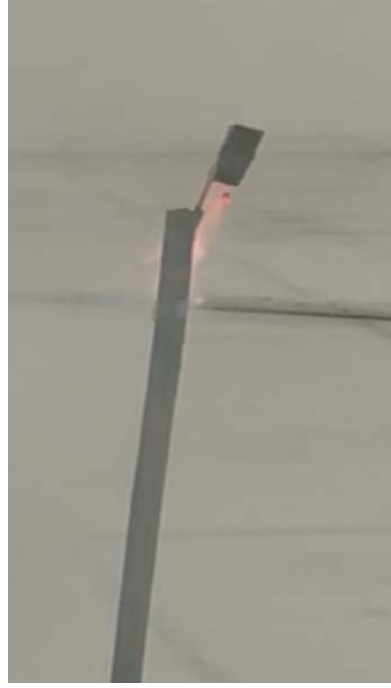

(b)

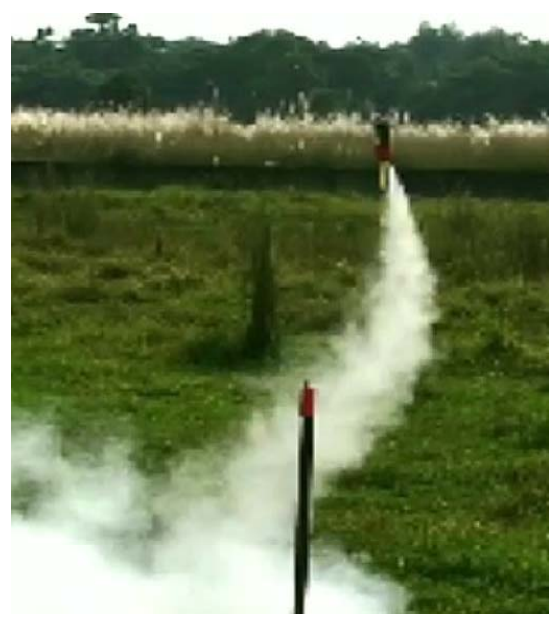

(c)

Fig. 10. (a) $20 \mathrm{~cm}$ stick stuck between fuel and launch platform. (b and c) Clockwise wobble with $10^{\circ}$ inclination from vertical axis. 


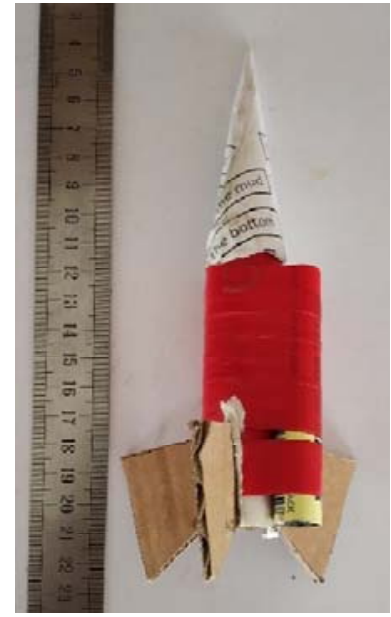

(a)

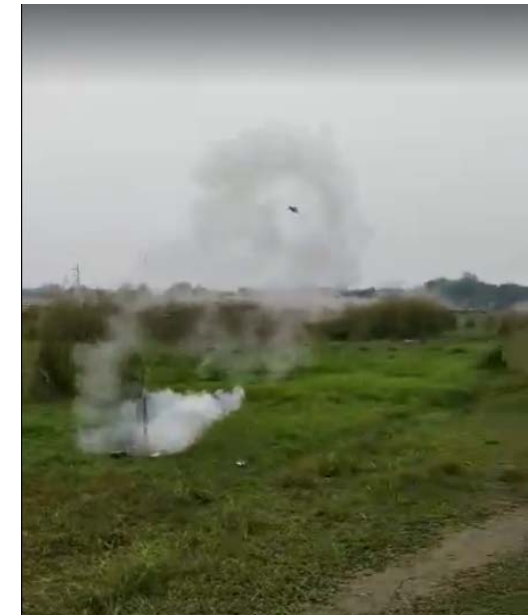

(b)

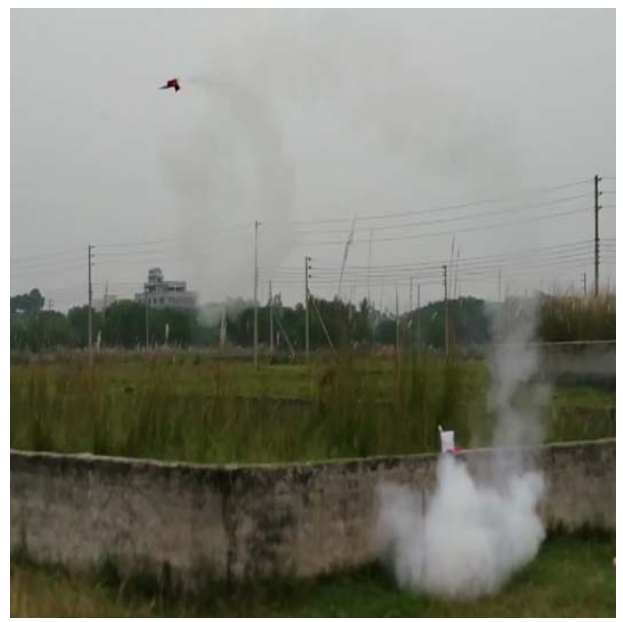

(c)

Fig. 11. (a) Asymmetric shaped prototype rocket. (b and c) Helical path due to asymmetric shape.

As shown in the Table 3, first five tests were failed. The possible reasons are the ratio of the white mixture, the width of the fuel pipe, selection of clay, position of nozzle and ignition.

Result obtained from the flight 9 as shown in fig. 12 indicates the test rocket fuel and the stick was stuck with the launch platform. Care should be taken on selecting the 1 meter long stick on launch pad. Data collected from the flight no. 9 was averaged to $0.2 \mathrm{sec}$ as shown in the table 4. Fig. 12 shows the path details of the flight no. 10. At $0.10 \mathrm{sec}$ the test rocket reaches $3 \mathrm{~m}$ altitude from the ground with $15^{0}$ inclinations from the vertical position. Small tilt at the beginning creates the angular displacement. At $1.4 \mathrm{sec}$ the test rocket reach at 1.5 meter altitude from the ground. The surrounding temperature on the flight day (October 25, 2019) was $29^{\circ} \mathrm{C}$. High pressure and abrupt changes of the temperature raised inside the payload (from 0.4 sec to 2 sec) indicates the material between the fuel and payload is not properly thermally insulated and isobaric process was not maintained. PVC material is used in flight 10 to overcome the issue. Average temperature and pressure recorded in flight no. 10 was $32.48^{\circ} \mathrm{C}$ and $101.128 \mathrm{~Pa}$ with standard deviation of 0.2 and 0.18 respectively. 


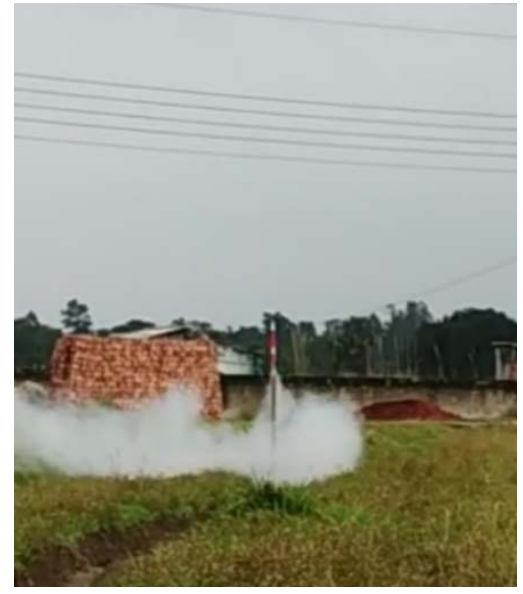

(a)

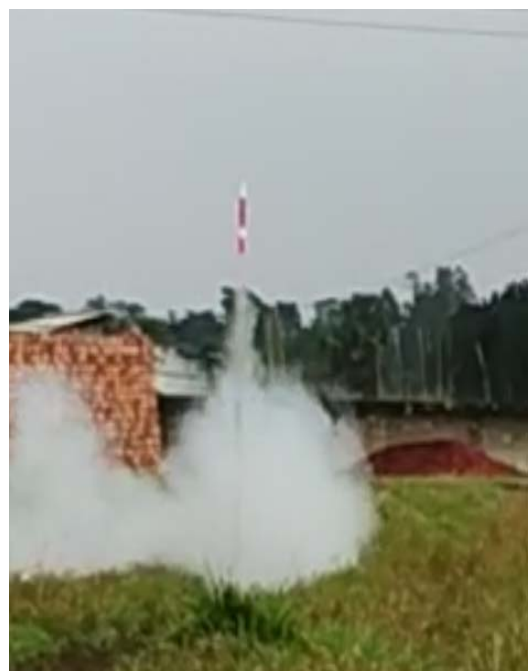

(c)

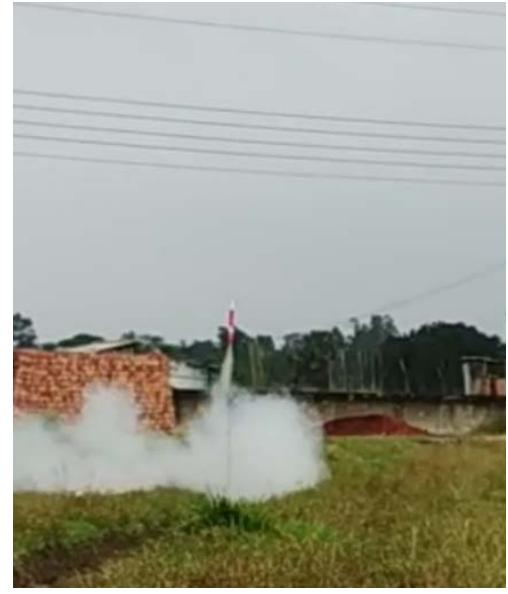

(b)

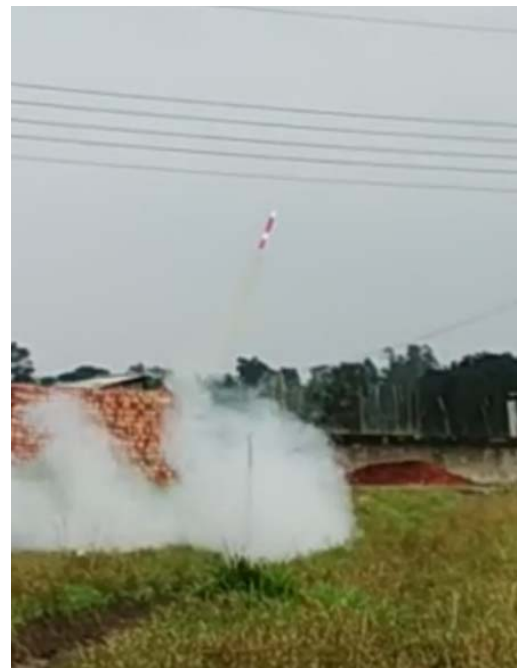

(d)

Fig. 12. (a) Stuck with launch platform. (b) Rocket at 1 second, (c) 1.2 second and (d) 1.4 second. TABLE 4. Data Recovered from Flight 11

\begin{tabular}{|c|c|c|c|}
\hline Time (s) & Temperature (C) & Pressure (atm) & Altitude (m) \\
\hline 0 & 29 & 1.02 & 0.3 \\
\hline 0.2 & 29 & 2.38 & 0.3 \\
\hline 0.4 & 29 & 2.38 & 0.3 \\
\hline 0.6 & 60 & 2.38 & 0.3 \\
\hline 0.8 & 60 & 1.02 & 0.3 \\
\hline 1 & 60 & 1.02 & 0.45 \\
\hline 1.2 & 60 & 1.02 & 0.6 \\
\hline 1.4 & 60 & 1.02 & 1.5 \\
\hline 1.6 & 60 & 1.02 & 1.4 \\
\hline 1.8 & 60 & 1.02 & 0.6 \\
\hline 2 & 60 & 1.02 & 0 \\
\hline
\end{tabular}


In the final test (test no. 10) all the problems were overcome. The test was performed with the parachute and payload. At $0.1 \mathrm{sec}$, the rocket titled to $10^{\circ}$ from the vertical axis (Fig. 13 (a)). At 1 sec, the rocket reaches 26 meters from the ground and the rocket path started to bend. It was found that the stick attached with the fuel was not straight. Therefore, due to the kinetic inertia and the bend of the stick, the path of the flight was bended (Fig. 13 (b) and (c)). The $30 \mathrm{~m}$ apogee was recorded at $1.75 \mathrm{sec}$ (Fig. 13).

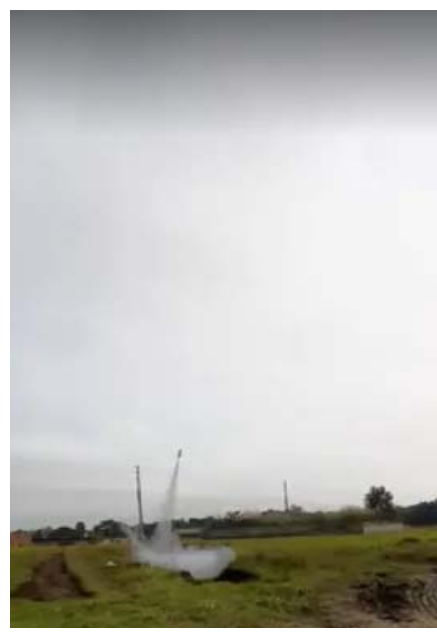

(a)

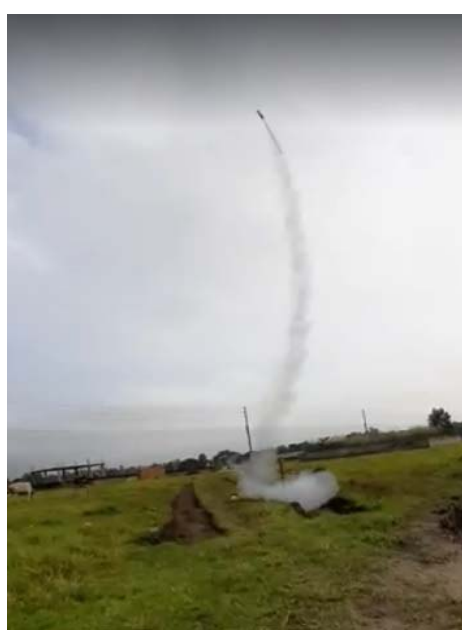

(b)

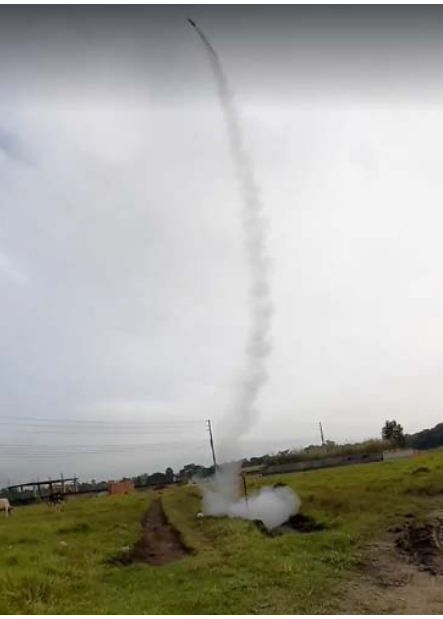

(c)

Fig. 13. (a) Path of the test rocket at 0.5 second, (b) at 1 second and (c) 1.5 second.

VIII. Data Analysis

Fig. 14 shows the flight duration and altitude of the experimental rocket and simulated rocket. Apogee and duration of the experimental rocket is lower than the result obtained from simulation.

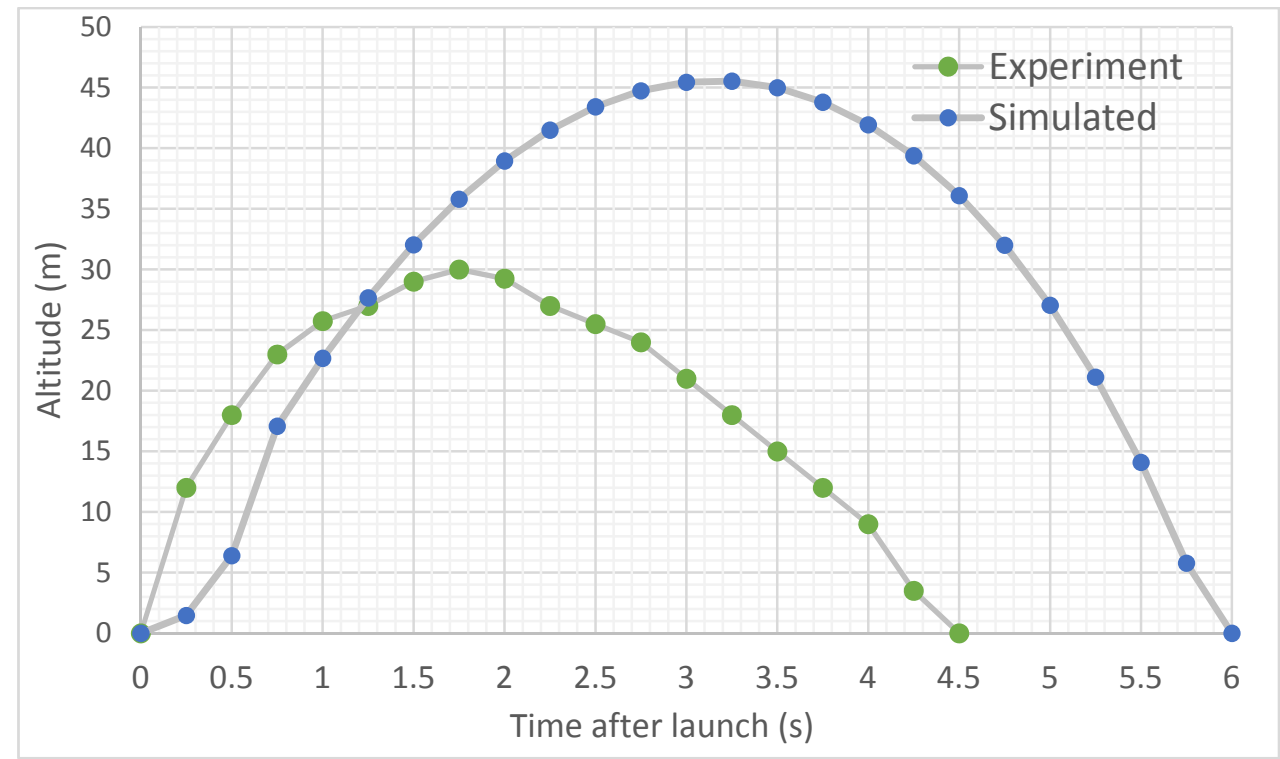

Fig. 14. Comparison of the simulated (blue) altitude versus the measured (green) altitude profile from the model rocket

Environmental data was also monitored $75 \mathrm{~s}$ before the rocket started to detach from the launch platform (Fig. 12). Since Potassium nitrate, sugar and clay produces CO, smoke and LPG, MQ-02 gas sensor is used to monitor the gases (measured in $\mathrm{ppm}$ ). The data are collected $0.5 \mathrm{~s}$ interval period operated by Arduino UNO which can only store in a micro SD card. The data indicates that the density of the CO, smoke and LPG went high from $5 \mathrm{~s}$ to $14 \mathrm{~s}, 40 \mathrm{~s}$ to $58 \mathrm{~s}$ and $70 \mathrm{~s}$ to $75 \mathrm{~s}$. This indicates that the burning occurs in three stages before deploying. 


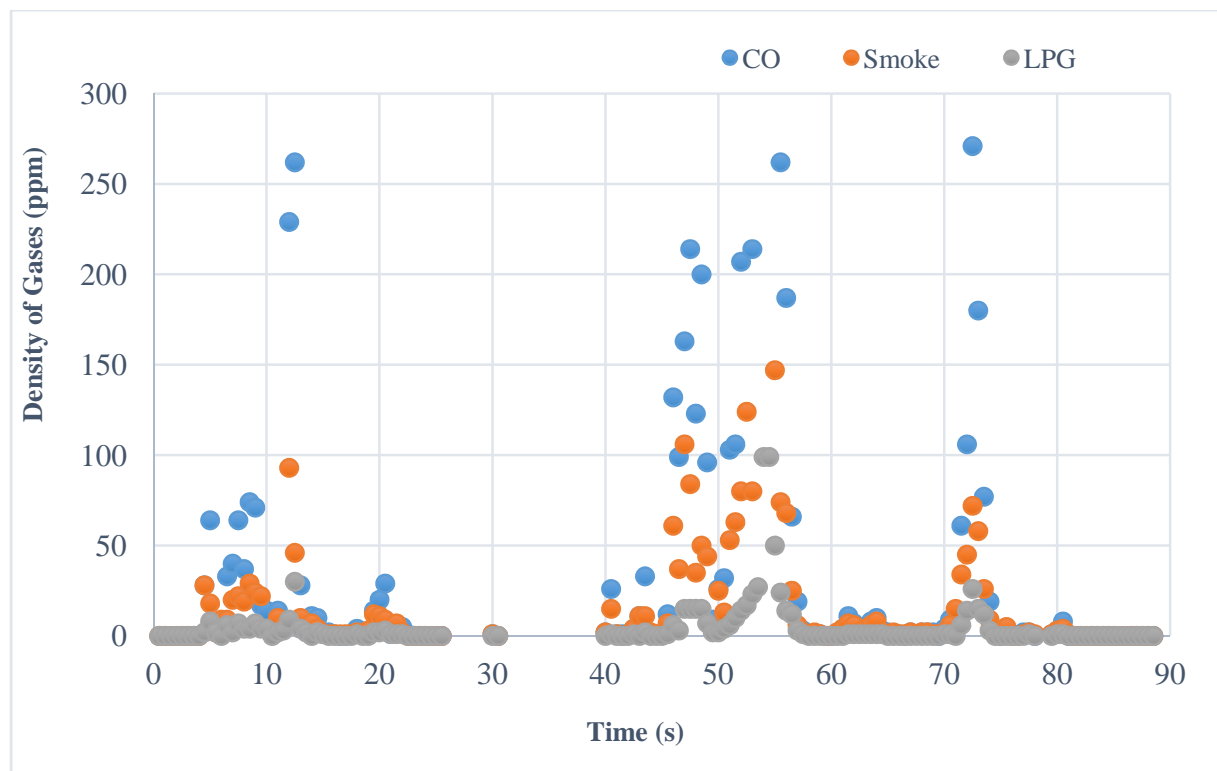

Fig. 12. Measurement of CO, smoke and LPG from MQ-02 Gas sensor before the launch of the rocket

\section{Cost ANALYsis}

Table 5 shows the price of the equipment used for rocket mission. The rocket fuel (Potassium Nitrate, Sugar, PVC pipe and wire) 400 BDT. As on 28 October 2019, 1 dollar is equivalent to 84.67 BDT. Therefore, the rocket without the sensor costs $\$ 4$ only. The total cost with the RPi, sensors and related materials to monitor the flight and environment takes 6520 BDT or \$ 77.04. Typical high-altitude balloon with 8 m diameter with sensors costs \$206 or 17,500 BDT. A meteorological drone with the sensor costs at least \$354.46 or 30,000 BDT. Therefore, this study indicates the sounding rocket is cost effective as well.

TABLE 4. Cost of the equipment

\begin{tabular}{|c|c|c|}
\hline Item Name & Quantity & Price (BDT) \\
\hline Raspberry Pi & 1 & 2250 \\
\hline Potassium Nitrate & 40 gm & 200 \\
\hline Battery & 1 & 1000 \\
\hline BMP 180, DHT 11, MQ 2 Sensor & 1 & 300 \\
\hline 2.6” PVC Pipe & 5 ” & 60 \\
\hline 9 ft Wire & 1 & 100 \\
\hline WIFI supporter & 1 & 1300 \\
\hline 32 GB SD card & 1 & 650 \\
\hline HDMI & 1 & 220 \\
\hline Mini USB to USB & 1 & 100 \\
\hline USB Hub & 1 & 300 \\
\hline Sugar & 40 gm & 40 \\
\hline TOTAL & & $\mathbf{6 5 2 0}$ \\
\hline
\end{tabular}

\section{CONCLUSION}

Several space borne satellites and land radars regularly monitor space weather [27]-[29]. On 11 May, 2018 Space-X successfully launched Bangabandhu Satellite-1 at Kennedy Space Center in Florida, USA. However, Bangladesh space agencies did not initiate to launch sounding rocket. Launching rocket is one of the challenging parts of the research as it involves high cost, cutting edge technology and precise calculation. This work will help the government agencies to initiate the sounding rocket project in Bangladesh. In near future, Bangladesh will be able to launch sounding rocket and low altitude spacecraft. Synthetic Aperture Radar (SAR) can be deployed as a payload in the sounding rocket to monitor flood, deforestation, landslides [30]. 


\section{ACKNOWLEDGEMENT}

The authors would like to thank Eastern University Authority, Bangladesh Metrological Department (BMD) for providing the temperature and Humidity data. Air Quality Index (AQI) data was collected from Airnow website developed by the US EPA, NOAA, NPS, tribal, State and Local Agencies. Iqbal Mahmud prepared the white mix of the rocket fuel and Md. Mafijul Islam Bhuiyan instructed to develop the IoT.

\section{REFERENCES}

[1] G.Seibert, "The History of Sounding Rockets and Their Contribution to European Space Research". Noordwijk, Netherlands: ESA Publications division, ESA History Study Reports, Nov. 2006.

[2] NASA Sounding Rockets Program Office, Suborbital \& Special Orbital Projects Directorate, NASA sounding rocket program handbook, NASA Goddard Space Flight Central, Wallops Flight Facility Wallops Island, Virginia: June. 2005.

[3] J. Prades, A. Ghiotto, E. Kerhervé, and K. Wu, "Broadband sounding rocket antenna for dual-band telemetric and payload data transmission”, IEEE Antennas and Wireless Propagation Letters, vol. 15, pp. 540-543, 2016.

[4] P. C. Tsai, H. P. Lin, D. B. Lin, and C. J. Chang, "Design and implement of transceiver system for hybrid rocket with coplanar wraparound antenna at 433MHz”, Antennas Propagation IET Microwaves, vol. 8, no. 13, pp. 1080-1090, Oct. 2014.

[5] M.E. Eckart, J.S. Adams, S.R. Bandler, S.E. Busch, J.A. Chervenak, A.J. Ewin, F.M.Finkbeiner, R.L.Kelley, C.A.Kilbourne, F.S.Porter, J.P.Porst, J.E.Sadleir, S.J.Smith, E.J.Wassell and E. Figueroa-Feliciano, "Development of test micro calorimeter arrays for the micro-x sounding rocket experiment”, IEEE Transactions on Applied Superconductivity, vol. 23, p. 2101705, Jun. 2013.

[6] K. Chiang, M. Psiaki, S. Powell, R. Miceli, and B. O’Hanlon, “GPS-based attitude determination for a spinning rocket”, IEEE Transactions on Aerospace and Electronic Systems, vol. 50, no. 4, pp. 2654-2663, Oct. 2014.

[7] R. Varaprasad, R. Gnanasambanthan, J. V. N. Ravikumar, C. J. R. Pamireddy, C. Ramsenthil, K. Haribabu, and V. S. Rao, "Groundbased real-time auto commanding system for ISRO advanced technology vehicles", IEEE Aerospace and Electronic Systems Magazine, vol. 29, no. 5, pp. 18- 24, May 2014.

[8] S. Patra and E. A. Spencer, "Plasma impedance probe: Simulations and comparison to sounding rocket mission data", IEEE Transactions on Plasma Science, vol. 41, no. 1, pp. 220-231, Jan. 2013.

[9] Laura Mazzino, Andreas Buttenschoen, Quinn Farr, Cory Hodgson, Wyatt Johnson, Ian Mann, Jonathan Rae. "Development of the University of Alberta High Altitude Balloons Program: Goals, Challenges, and Achievements”. Next-Generation Suborbital Researchers Conference, held February 27-29, 2012 in Palo Alto, California.

[10] Mazzino, M. L. P.; Miles, D.; Wood, T.; Rae, J.; Murphy, K.; Mann, I. R. "Beginning of a Student Experimental Space Science High Altitude Balloon Program at University of Alberta”. Next-Generation Suborbital Researchers Conference, held February 18-20, 2010 in Boulder, Colorado. LPI Contribution No. 1534, p.58.

[11] Kardasz, P., Doskocz, J., Hejduk, M., Wiejkut, P., Zarzycki, H.: Drones and possibilities of their using. Journal of Civil \& Environmental Engineering, vol. 6, pp.1-7, Jan. 2016.

[12] (Oct. 14, 2019) Air Quality Index of Dhaka. [Online]. Available: https://www.airnow.gov/index.cfm?action=airnow.global_summary\#Bangladesh\$Dhaka

[13] (Oct. 14, 2019) The website of Bangladesh Metrological Department. [Online]. Available: http://bmd.gov.bd

[14] F. Rockets (Oct. 14, 2019). Basic components of a sport rocket. [Online]. Available: http://www.flyrockets.com/work.asp

[15] (Oct. 14, 2019) Richard Nakka's Experimental Rocketry Web Site. [Online]. Available: http://www.nakka-rocketry.net

[16] (Oct. 14, 2019) The Centuri Model Rocket Designers Manual. [Online]. Available: http://www.ninfinger.org/rockets/catalogs/centuridesign/cendesign.html

[17] P.H. Dana and B.M. Penrod, "The role of GPS in precise time and frequency dissemination,” GPS World,1990.

[18] Miles, David \& Mann, Ian \& Knudsen, David \& McWilliams, Kathryn \& Dahle, Kolbjorn \& Grande, Jøran \& Moen, Joran \& Thrane, Eric \& Hansen, Arne \& Løvhaug, Unni \& Rae, I. Jonathan \& Kale, Andy \& Jackel, Brian \& Kburnchill, Johnathan \& Shahsavar, Aarya \& Grono, Eric \& Cupido, Collin. "The Canada/Norway Student Sounding Rocket Program (CaNoRock)," Physics in Canada (PIC),vol. 72, no. 1, 2016.

[19] (Oct. 28, 2019) UK Met office Website. [Online]. Available: https://www.metoffice.gov.uk/weather/guides/observations

[20] (Oct. 28, 2019) National Centers For Environmental Information Data Access. [Online]. Available: https://www.ncdc.noaa.gov/dataaccess

[21] (Oct. 28, 2019) Windy Website. [Online]. Available: https://www.windy.com.

[22] (Oct. 28, 2019) DroneBot Workshop Website. [Online]. Available: https://dronebotworkshop.com/raspberry-pi-microcomputer

[23] (Oct. 14, 2019). Model rocket engine, Wikimedia. [Online]. Available: https://commons. wikimedia.org/wiki/File:Model-rocketengine.svg

[24] ESTES, Catalogs. (Oct. 13,2016) ESTES, 2016. [Online]. Available: https://estesrockets.com/wpcontent/uploads/Catalogs/Estes_2016_Catalog.pdf

[25] Estes Model Rocketry Technical Manual. (Oct. 14, 2019).[Online]. Available: https://estesrockets.com/wpcontent/uploads/Educator/2819_Estes_Model_Rocketry_Technical_Manual.pdf

[26] Simon Box, Christopher M. Bishop and Hugh Hunt, "Stochastic Six-Degree-of-Freedom Flight Simulator for Passively Controlled High-Power Rockets,” Journal of Aerospace Engineering, vol 24. Jan. 2011.

[27] Hoque, S.A. and Ahmed, T. "Adapting the NeQuick 2 Model to GPS Derived TEC Data at a given Location,” The AIUB Journal of Science and Engineering (AJSE), vol. 15, no. 1. pp.135-141. 2016.

[28] Hoque, S.N.M. A. "Improvement of B2bot correction factor for NeQuick 2 during the high solar activity at Saint Croix," Journal of Advanced Research Design. Vol 27, Issue 1 .pp.19-26. 2016

[29] Hoque, S.N.M. A. and Fenrich, F. J. "A New Technique for Understanding Magnetosphere-Ionosphere Coupling Using Directional Derivatives of SuperDARN Convection Flow,” Journal of Astrophysics and Astronomy. Vol. 39, pp.70. 2018.

[30] S. N. M. Azizul Hoque, Mafijul Islam Bhuiyan, "Flood monitoring and forecasting using SAR and meteorological data: A case study. Gobeshona 5,” The Gobeshona Annual Conference 2019, ICCCAD . Independent University, Bangladesh, pp. 58-59. Jan. 2019. 